\title{
The Effect of Continuous Field Block through Intercostal Muscles after Atrial Septal Defect Closure via a Mini-Right Thoracotomy in Pediatric Patients
}

\author{
Kenji Suzuki ${ }^{1}$, Takashi Sasaki ${ }^{1}$, Yasuo Miyagi ${ }^{1}$, Keisuke Mori ${ }^{2}$, \\ Hiroaki Kishikawa ${ }^{2}$, Yosuke Ishii ${ }^{1}$, Atsuhiro Sakamoto ${ }^{2}$ and Takashi Nitta ${ }^{1}$ \\ ${ }^{1}$ Department of Cardiovascular Surgery, Nippon Medical School, Tokyo, Japan \\ ${ }^{2}$ Department of Anesthesiology, Nippon Medical School, Tokyo, Japan
}

\begin{abstract}
Background: Postoperative pain management in thoracotomy patients often is difficult. Furthermore, pediatric patients present more challenges because of their inability to effectively communicate their pain intensity. The purpose of this study was to evaluate the use of continuous field block through intercostal muscles as postoperative pain management in pediatric thoracotomy.
\end{abstract}

Methods: Between 2014 and 2018, 11 patients underwent an ASD closure using a cardiopulmonary bypass via a mini-right thoracotomy through the fourth intercostal space. At the time of chest closure, a single-shot field block via the fourth intercostal muscles was performed with levobupivacaine $(0.6 \mathrm{mg} /$ $\mathrm{kg}$ ). The first five patients were only given the single-shot field block (Single group). The remaining six patients were given levobupivacaine continuously $(0.1 \mathrm{mg} / \mathrm{kg} / \mathrm{hr})$ through an indwelling catheter until the chest tube removal (Continuous group). The groups' vital signs, total amounts of acetaminophen used, postoperative courses were compared.

Results: Although the heart rate did not differ between the groups, the respiratory rate was significantly higher in the Single group versus the Continuous group at 16 and $32 \mathrm{hr}$ post-surgery (35.6 $\pm 9.7 /$ $\min$ vs. $18.5 \pm 4.7 / \mathrm{min} ; \mathrm{p}=0.007,43.0 \pm 10.4$ vs. $25.3 \pm 3.1 ; \mathrm{p}=0.042$, respectively). The accumulated dosage of acetaminophen given by postoperative day 2 was significantly higher in the Single group versus the Continuous group $(55.3 \pm 22.1 \mathrm{mg} / \mathrm{kg}$ vs. $7.8 \pm 17.4 \mathrm{mg} / \mathrm{kg} ; \mathrm{p}=0.012)$.

Conclusions: Continuous field block via intercostal muscles after ASD closure via a mini-right thoracotomy in children was effective to stabilize the vital signs and reduce the analgesic medication use.

(J Nippon Med Sch 2021; 88: 347-353)

Key words: congenital heart defects, local anesthesia, thoracotomy, minimally invasive surgical procedures

\section{Introduction}

Thoracotomy approach has been applied for simple cardiac surgeries such as atrial septal defect closure or ventricular septal defect closure in children. The advantages of thoracotomy over the standard sternotomy are minimal trauma, better postoperative recovery, and improved cosmetic results ${ }^{1}$. However, postoperative pain management after thoracotomy presents challenges because of the rich innervation of the thorax ${ }^{2}$. Poor pain control can adversely affect the ability to cough and depth of breathing, resulting in respiratory complications such as hypoxia and atelectasis, which preclude early recovery, Although systemic opioid based analgesia has been the first choice after cardiac surgery in children, it has higher incidence of nausea or vomiting.

Our strategy for (of) the minimally invasive closure of an atrial ASD in children is designed to avoid sternotomy, peripheral cannulation, and opioid use after sur-

Correspondence to Dr. Kenji Suzuki, Department of Cardiovascular Surgery, Nippon Medical School, 1-1-5 Sendagi, Bunkyo-

ku, Tokyo 113-8603, Japan

E-mail: suzuki@nms.ac.jp

https://doi.org/10.1272/jnms.JNMS.2021_88-507

Journal Website (https://www.nms.ac.jp/sh/jnms/) 
Table 1 Patient characteristics

\begin{tabular}{lccc}
\hline & Single group $(\mathrm{n}=5)$ & Continuous group $(\mathrm{n}=6)$ & $\mathrm{p}$-value \\
\hline Age, yrs & $5.2 \pm 4.1(1-11)$ & $5.0 \pm 3.2(2-11)$ & 0.938 \\
Female/male & $5 / 0$ & $4 / 2$ & 0.454 \\
Weight, $\mathrm{kg}$ & $17.3 \pm 11.5(6.5-35)$ & $18.7 \pm 9.5(10.8-39)$ & 0.859 \\
ASD secundum type & 4 & 6 & 0.454 \\
\hline
\end{tabular}

Values are mean \pm SD (range). ASD: atrial septal defect.

gery, and the strategy involves the use of a small skin incision, a thoracotomy, a muscle-sparing approach (except for the separation of intercostal muscles), central cannulation, and sufficient pain management without the use of an opioid after surgery. For postoperative pain control, a small catheter is put into the intercostal muscles and an analgesic agent is given continuously.

Although regional analgesia after pediatric cardiac surgery is widely and increasingly adopted world-wide ${ }^{5,6}$, to the best of our knowledge, the report of a continuous field block in intercostal muscles after cardiac surgery via thoracotomy in pediatric patients is rare. Therefore, we conducted the present study to evaluate the effect of a continuous field block in intercostal muscles on the postoperative course after ASD closure via a mini-right thoracotomy in pediatric patients.

\section{Patients and Methods}

\section{Patients}

This study was performed in accordance with the guidelines of the Declaration of Helsinki and was approved by the Ethics Committee of the Nippon Medical School in Tokyo, Japan (reference number: 29-01-889). This was a retrospective study of 11 patients (nine girls, two boys) who weighed $<40 \mathrm{~kg}$ and underwent ASD closure via a mini-right thoracotomy at our institute between December 2014 and December 2018. All thoracotomy incisions were performed in the fourth intercostal space. In all the patients, a field block via fourth intercostal muscles (which aims to block an intercostal nerve) was performed at the end of surgery with levobupivacaine $(0.6 \mathrm{mg} / \mathrm{kg})$.

In the first five patients, only the single-shot levobupivacaine was given (the Single group). In the latter six patients, levobupivacaine was given continuously through an indwelling catheter until the removal of the chest tube (the Continuous group). As shown in Table 1, the mean age at the operation was $5.2 \pm 4.1$ years old (range: $1-11$ years old) in the Single group and $5.0 \pm 3.2$ years old (211 years) in the Continuous group $(p=0.938)$. The mean body weight in the two groups did not differ significantly at $17.3 \pm 11.5$ (6.5 to 35$)$ and $18.7 \pm 9.5 \mathrm{~kg}$ (10.8 to $39)$, respectively $(\mathrm{p}=0.859)$.

\section{Morphology}

One patient in the Single group had an inferior sinus venosus-type ASD and patent fossa ovalis, and the other 10 patients had an isolated secundum-type ASD.

\section{Surgical Technique}

In all patients, the skin incision was made longitudinally in the anterior subaxillary region. The length of the incision was limited to $5 \%-7 \%$ of the patient's height. The major pectoralis muscle and anterior serratus muscle were preserved, but the fourth intercostal muscles were separated widely instead. The cardiopulmonary bypass was initiated with aortic perfusion and direct bicaval drainage. The intracardiac repair was performed during cardiac arrest.

A saline was added to $0.25 \%$ levobupivacaine (POPSCAINE 0.25\%, Maruishi Pharmaceutical. Co., Osaka, Japan) and made diluted $0.1 \%$ levobupivacaine. For postoperative pain control, at the time of chest closure, the five patients in the Single group were given only a single-shot field block in the fourth intercostal muscles with $0.1 \%$ levobupivacaine $(0.6 \mathrm{mg} / \mathrm{kg}=0.6 \mathrm{~mL} / \mathrm{kg})$ via a 23-gauge (ga.) needle. The six patients in the Continuous group were given $0.1 \%$ levobupivacaine continuously $(0.1 \mathrm{mg} / \mathrm{kg} / \mathrm{hr}=0.1 \mathrm{~mL} / \mathrm{kg} / \mathrm{hr})$ through an indwelling peripheral nerve block catheter (Contiplex, B. Braun Melsungen, Melsungen, Germany; 18 ga.) after the same single-shot field block as that received by the Singlegroup patients (Fig. 1). A nerve block catheter was inserted toward a paravertebral space between internal and external intercostal muscles at the fourth intercostal space.

After that, the drain, made of silicon rubber and 15-Fr or 19-Fr in accord with the patient's body size was inserted through the fifth intercostal space, followed by chest closure.

\section{Postoperative Care}

All patients were administered a continuous dexmede- 


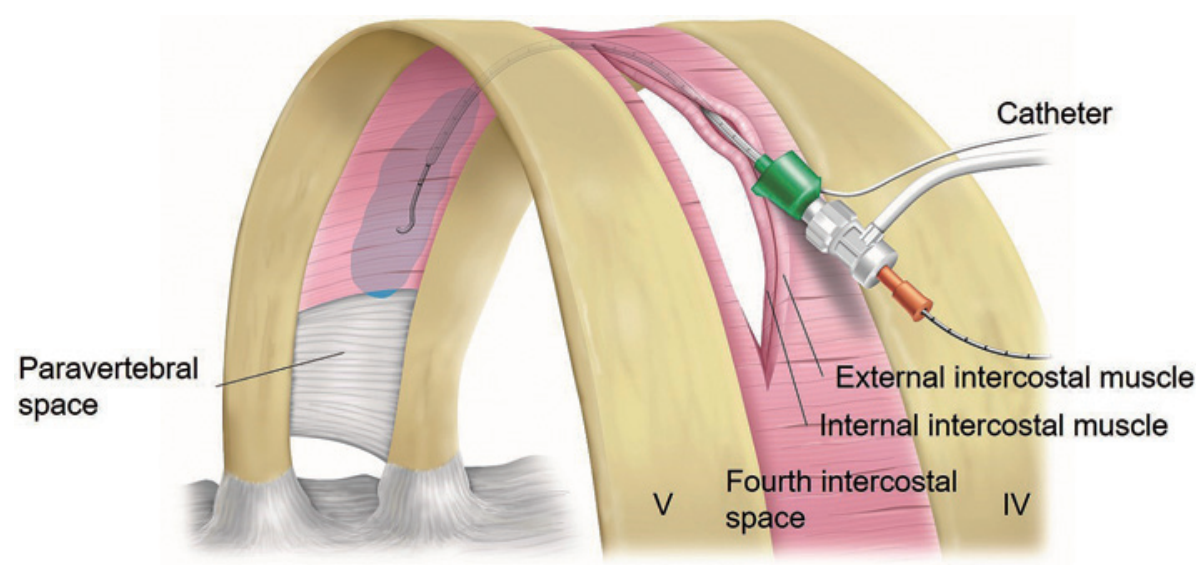

Fig. 1 An indwelling peripheral nerve block catheter was inserted toward a paravertebral space between internal and external intercostal muscles at the fourth intercostal space. The patients in the Continuous group were given levobupivacaine continuously through the catheter following a shot field block.

Table 2 Operation data

\begin{tabular}{lccc}
\hline & Single group $(\mathrm{n}=5)$ & Continuous group $(\mathrm{n}=6)$ & p-value \\
\hline Operation time, $\min$ & $209.0 \pm 42.2(176-291)$ & $310.0 \pm 56.9(224-407)$ & 0.014 \\
Cardiopulmonary bypass time, $\mathrm{min}$ & $63.2 \pm 23.2(40-105)$ & $87.5 \pm 19.7(65-125)$ & 0.135 \\
Cross-clamp time, $\min$ & $31.6 \pm 17.7(11-63)$ & $30.0 \pm 12.6(17-56)$ & 0.883 \\
Intraoperative fentanyl dose, $\mu \mathrm{g} / \mathrm{kg}$ & $10.3 \pm 2.9(7.1-15.6)$ & $14.5 \pm 7.3(4.6-25.8)$ & 0.558 \\
\hline
\end{tabular}

Values are mean \pm SD (range).

tomidine infusion $(0.4-0.7 \mu \mathrm{g} / \mathrm{kg} / \mathrm{hr})$ during their postoperative stay in the intensive care unit. Acetaminophen (10 mg/kg) was given by oral, rectal, or intravenous administration as needed. No other analgesic agent including opioid was given.

\section{Data Collection and Analysis}

The operation data such as the operation time, the cardiopulmonary bypass time, the cross-clamp time, and the dosage of fentanyl given intraoperatively were collected. The vital signs (heart rate and respiratory rate) were collected before the operation and every $8 \mathrm{hr}$ after the operation until the removal of the chest tube and indwelling peripheral nerve block catheter. The duration of intubation was defined as the time between the end of the operation and the extubation.

The data are presented as the mean \pm standard deviation (SD) and range. The two-group comparisons were done with the Mann-Whitney U-test and the 2x2 Chi square test for patient characteristics and operation data. The comparisons between the values before and after the operation were performed with a one-way ANOVA. For all tests, a value of $\mathrm{p}<0.05$ was considered significant.

\section{Results}

There was no death, no re-operation, and no complication such as pneumothorax, bleeding, and neurological adverse events. The mean operation time, cardiopulmonary bypass time, cross-clamp time, and dosage of fentanyl given intraoperatively are provided in Table 2 . There were no significant differences in the cardiopulmonary bypass time, the cross-clamp time or the dosage of fentanyl given intraoperatively between the Single and Continuous groups.

The details of the patients' postoperative courses are given in Table 3. The average duration of intubation was $167.8 \pm 162.6 \mathrm{~min}(30-487)$ in the Single group and 196.0 $\pm 90.0 \mathrm{~min}(30-292)$ in the Continuous group $(\mathrm{p}=0.764)$. The chest tube was removed postoperatively at $1.6 \pm 0.5$ days (1-2) in the Single group and at $2.0 \pm 0$ days (all 2 days) in the Continuous group. The catheter for the continuous field block was removed at $2.2 \pm 0.4$ days (2-3) in the Continuous group. Transfusion for anemia was needed in two patients in the Single group.

The accumulated dosage of acetaminophen given by postoperative day 2 was $55.3 \pm 22.1 \mathrm{mg} / \mathrm{kg}$ (38.5-97.8) in the Single group and significantly less at $7.8 \pm 17.4 \mathrm{mg} /$ 
Table 3 Postoperative course

\begin{tabular}{|c|c|c|c|}
\hline & $\begin{array}{l}\text { Single group } \\
(n=5)\end{array}$ & $\begin{array}{l}\text { Continuous group } \\
\qquad(\mathrm{n}=6)\end{array}$ & p-value \\
\hline Duration of intubation, min & $167.8 \pm 162.6(30-487)$ & $196.0 \pm 90.0(30-292)$ & 0.764 \\
\hline Chest tube removal, days & $1.6 \pm 0.5(1-2)$ & $2.0 \pm 0($ all 2$)$ & 0.178 \\
\hline Duration of continuous intercostal nerve block, days & & $2.2 \pm 0.4(2-3)$ & \\
\hline Transfusion including intraoperation & 2 & 0 & 0.182 \\
\hline $\begin{array}{l}\text { Accumulated dosage of acetaminophen given by postoperative } \\
\text { day } 2, \mathrm{mg} / \mathrm{kg}\end{array}$ & $55.3 \pm 22.1(38.5-97.8)$ & $7.8 \pm 17.4(0-46.6)$ & 0.012 \\
\hline Hospital stay, days & $6.2 \pm 0.4(6-7)$ & $5.5 \pm 1.4(4-8)$ & 0.323 \\
\hline
\end{tabular}

Values are mean $\pm \mathrm{SD}$ (range).

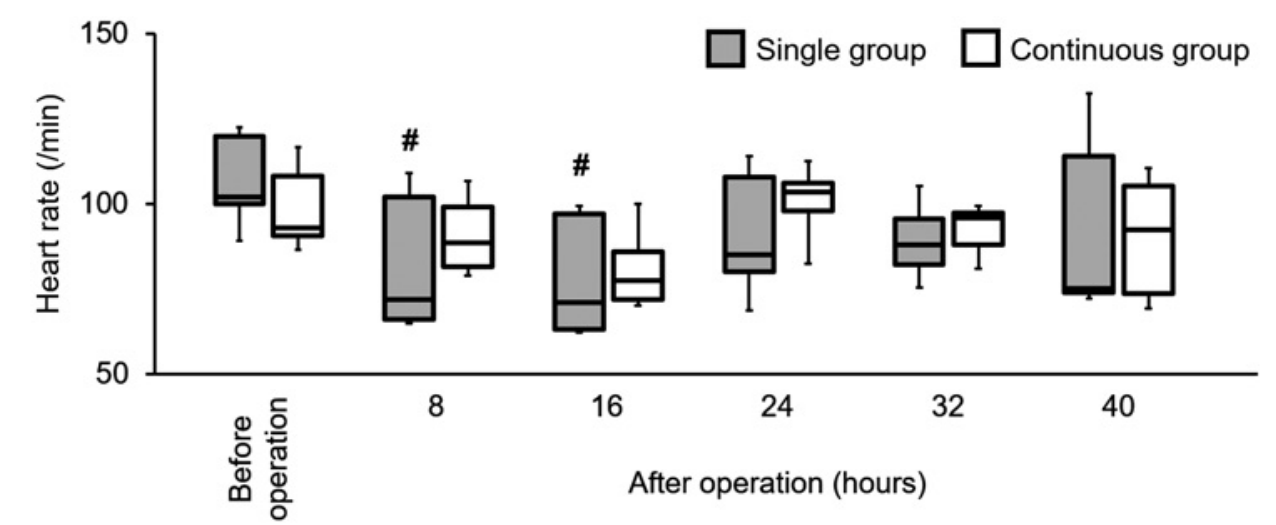

Fig. 2 There was no significant between-group difference in the median heart rate at before and after the operation. The median heart rate in the Single group at 8 and $16 \mathrm{hr}$ after the operation were significantly lower than the value before the operation $(8 \mathrm{hr}$ : $\mathrm{p}=0.02716 \mathrm{hr}: \mathrm{p}=0.009)$. \# $<<0.05$ vs. the pre-operation value.

$\mathrm{kg}(0-46.6)$ in the Continuous group $(\mathrm{p}=0.012)$. The average length of hospital stay was $6.2 \pm 0.4$ days (6-7) in the Single group and $5.5 \pm 1.4$ days (4-8) in the Continuous group $(\mathrm{p}=0.323)$.

The median heart rates in the Single and Continuous groups are illustrated in Figure 2; there was no significant difference between the two groups. The median heart rate of the Single group at 8 and $16 \mathrm{hr}$ after the operation were significantly lower than the value before the operation (before operation: $105.6 \pm 15.1 / \mathrm{min}, 8 \mathrm{hr}: 83.6$ \pm 20.5; $\mathrm{p}=0.027,16 \mathrm{hr}: 78.8 \pm 16.8 ; \mathrm{p}=0.009$ ).

The median respiratory rates of the Single and Continuous groups are provided in Figure 3. The respiratory rate was significantly lower in the Continuous group at $16 \mathrm{hr}$ and $32 \mathrm{hr}$ post-surgery $(35.6 \pm 9.7 / \mathrm{min}$ vs. $18.5 \pm$ $4.7 / \mathrm{min}, \mathrm{p}=0.007 ; 43.0 \pm 10.4$ vs. $25.3 \pm 3.1, \mathrm{p}=0.042$, respectively).

\section{Discussion}

The results of this retrospective study demonstrated that the respiratory rate and the rescue usage of aceta- minophen were significantly lower in the patients for whom a continuous field block was administered, and these data imply that a continuous field block provides effective analgesia for pediatric patients undergoing ASD closure via a mini-right thoracotomy. The technique described herein was also safe, because the insertion of the catheter was achieved under direct observation, and there were no complications.

There was no significant difference in the postoperative heart rate between the Single and Continuous groups, because the continuous dexmedetomidine infusion reduced the heart rate in both groups. Earlier studies demonstrated the heart rates were lower in patients who received a dexmedetomidine infusion ${ }^{7-9}$. In contrast, the pain management due to the continuous field block in the present study reduced the respiratory rate in the Continuous group. Tarikci et al. reported dexmedetomidine infusion had no significant effect on the patients' respiratory rate ${ }^{7}$.

We emphasize the necessity of effective pain control for minimally invasive cardiothoracic surgery in children. 


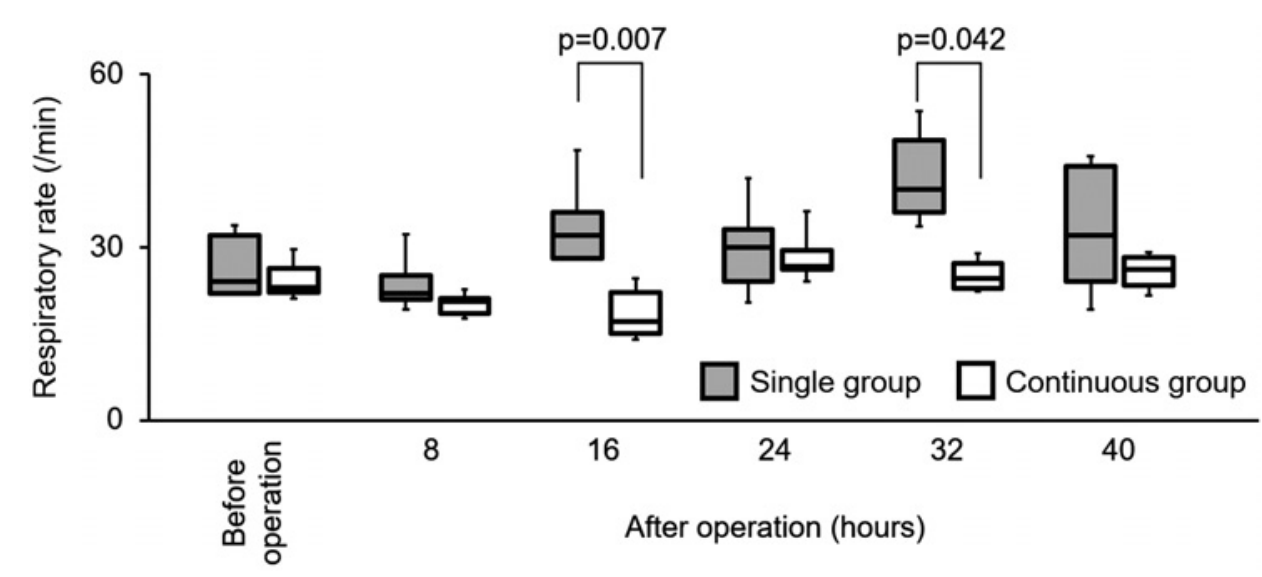

Fig. 3 The median respiratory rate after the operation was significantly lower in Continuous group at 16 and $32 \mathrm{hr}$ after the operation ( $\mathrm{p}=0.007$ and $\mathrm{p}=0.042$ respectively).

At our hospital, ASD closures are performed with an incision that is within $5 \%-7 \%$ of the patient's height, and the closure thus requires an extensive subcutaneous dissection and wide separation of intercostal muscles. Deep tissue disorder as well as the skin incision can cause postoperative pain ${ }^{10}$. Fitzgerald et al. ${ }^{11}$ showed that the immaturity of sensory processing in children leads to lower thresholds for excitation and sensitization, therefore potentially maximizing the central effects of these tissue-damaging inputs. Moreover, early damage in infancy can lead to prolonged structural and functional alterations in pain pathways that can last into adult life. Anand et al. ${ }^{3,4}$ noted that in children undergoing cardiac surgery, the physiologic responses to stress are attenuated by deep anesthesia and postoperative analgesia, and pain control may reduce the vulnerability of these children to complications and may reduce mortality.

Postoperative pain control in pediatric cardiac surgery is difficult to achieve and requires careful consideration for the following reasons. Bleeding, inadvertent intravascular injection and nerve injury that are concealed from view are concerns in the use of regional block techniques ${ }^{6}$. Similarly, an epidural hematoma is a concern in the administration of epidural analgesia during surgeries involving a cardiopulmonary bypass ${ }^{12}$. On the other hand, the use of intravenous patient-controlled analgesia for children is still controversial, as earlier reports emphasized the life-threatening risks associated with patient-controlled analgesia by a parent and/or nurse to treat pain in young children ${ }^{13,14}$. Additionally, the systematic administration of acetaminophen sometimes results in uncertain effects, and the dosage needed for sufficient efficacy must be considered ${ }^{5,6,10}$.

A continuous nerve block through an indwelling inter- costal catheter has now been used in lung surgery for several years. Previous studies ${ }^{15,16}$ showed that such a nerve block can ameliorate patients' postoperative pain. A continuous intercostal nerve block also appears to be a safe and useful technique for the supplementation of postoperative analgesia in pediatric patients with the Nuss procedure ${ }^{11}$. Specifically, patients undergoing a thoracotomy may suffer from severe postoperative pain, but adequate pain control can be obtained by analgesia with a continuous intercostal nerve block ${ }^{15,17}$. Single-shot peripheral regional blocks using levobupivacaine provide analgesia for only 12-16 $\mathrm{hr}^{18,19}$.

By contrast, adequate postoperative analgesia, especially during the first $48 \mathrm{hr}$, reduces the stress of the surgical procedure such as changes in the endocrine, metabolic, and inflammatory systems ${ }^{19,20}$. We sought to block the intercostal nerve by infiltration anesthesia. As we did not confirm whether the edge of the indwelling catheter was in the paravertebral space or the neurilemma of the intercostal nerve, we named our technique "field block via intercostal muscles."

The between-group difference in the operation time was caused by a technical issue regarding the insertion of the indwelling catheter, which took almost 10 minutes. In addition, the operations for the Single group (the first five patients) were performed by the same surgeon, whereas those for the Continuous group (the latter six patients) were performed by two surgeons including a clinical fellow.

A major component of a nerve block using an intercostal catheter may spread into surrounding tissue as well as the intercostal space with the catheter. Mowbray et al. ${ }^{21}$ stated that the spread of an analgesic agent involved one or two intercostal spaces; simultaneously, the agent 
spread medially to the paravertebral space, and then it spread in both caudad and cephalad directions to reach between two and five vertebrae. In addition, an analgesic agent was observed crossing the anterior surface of the vertebrae to reach the contralateral aspect $\mathrm{t}^{22}$.

Our present study's limitations include the small number of cases $(n=11)$, the issue regarding the location of the tip of the block catheter, and the lack of a numerical or other objective pain evaluation method. Our patient series is too small to allow firm conclusions about the relationship between a continuous field block and reduced stress responses. There is the possibility of the type 2 error, i.e. of our analyses being "underpowered" with a small number of cases which has no significant difference in particular. A type 2 error may also include instability (declining reproducibility) even for a result which shows a significant difference. However, the differences between the Single and Continuous groups suggested that the continuous field block might reduce postoperative pain in children who have undergone cardiac surgery via a thoracotomy. In any case, caution is necessary for clinical practices applying these results, and analyses in further large-scale studies are necessary.

Secondly, the location of the tip of the block catheter was not confirmed using x-ray or echography; however, we confirmed under direct vision that the tip of the catheter was left in the intercostal muscles and did not appear in the chest cavity. Finally, we did not perform a quantitative assessment of analgesia using the FLACC (face, legs, activity, cry and consolability) Scale or the Nonverbal Pain Scale (NVPS).

We conclude that a continuous field block via intercostal muscles after the closure of an atrial septum defect through a mini-right thoracotomy in children was effective to stabilize the patients' vital signs and reduce the need for post-operative analgesic medication.

Acknowledgements: We are grateful to Dr. Toshiaki Otsuka, MD, PhD, Department of Hygiene and Public Health, Nippon Medical School, for the statistical rationale and supervision.

Conflict of Interest: All authors have no conflicts of interest to report.

\section{References}

1. Liava'a M, Kalfa D. Surgical closure of atrial septal defects. J Thorac Dis [Internet]. 2018 Sep;10(Suppl 24):S 2931-9. Available from: http://www.ncbi.nlm.nih.gov/pu bmed/30305953

2. Stecco C, Sfriso MM, Porzionato A, et al. Microscopic anatomy of the visceral fasciae. J Anat [Internet]. 2017 Jul; 231(1):121-8. Available from: http://www.ncbi.nlm.nih.go $\mathrm{v} /$ pubmed/28466969

3. Anand KJ, Hickey PR. Halothane-morphine compared with high-dose sufentanil for anesthesia and postoperative analgesia in neonatal cardiac surgery. $\mathrm{N}$ Engl J Med [Internet]. 1992 Jan 2;326(1):1-9. Available from: http://w ww.ncbi.nlm.nih.gov/pubmed/1530752

4. Anand KJ, Sippell WG, Aynsley-Green A. Randomised trial of fentanyl anaesthesia in preterm babies undergoing surgery: effects on the stress response. Lancet [Internet]. 1987 Jan 31;1(8527):243-8. Available from: http://www.nc bi.nlm.nih.gov/pubmed/20928962

5. Chaudhary V, Chauhan S, Choudhury M, Kiran U, Vasdev S, Talwar S. Parasternal intercostal block with ropivacaine for postoperative analgesia in pediatric patients undergoing cardiac surgery: a double-blind, randomized, controlled study. J Cardiothorac Vasc Anesth [Internet]. 2012 Jun;26(3):439-42. Available from: http://www.ncbi.nl m.nih.gov/pubmed/22176767

6. Mittnacht AJC, Shariat A, Weiner MM, et al. Regional techniques for cardiac and cardiac-related procedures. J Cardiothorac Vasc Anesth [Internet]. 2019 Feb;33(2):53246. Available from: http://www.ncbi.nlm.nih.gov/pubme d/30529177

7. Tarikci Kilic E, Aydin G. Effects of dexmedetomidine infusion during spinal anesthesia on hemodynamics and sedation. Libyan J Med [Internet]. 2018 Dec;13(1):1436845. Available from: http://www.ncbi.nlm.nih.gov/pubmed/2 9457538

8. Kang D, Lim C, Shim DJ, et al. The correlation of heart rate between natural sleep and dexmedetomidine sedation. Korean J Anesthesiol [Internet]. 2019 Apr;72(2):1648. Available from: http://www.ncbi.nlm.nih.gov/pubme d/30481949

9. Gong M, Man Y, Fu Q. Incidence of bradycardia in pediatric patients receiving dexmedetomidine anesthesia: a meta-analysis. Int J Clin Pharm [Internet]. 2017 Feb;39(1): 139-47. Available from: http://www.ncbi.nlm.nih.gov/pu bmed/28040841

10. Brennan TJ. Pathophysiology of postoperative pain. Pain. 2011 Mar;152(3 Suppl):S33-40.

11. Fitzgerald M, Beggs S. The neurobiology of pain: developmental aspects. Neuroscientist [Internet]. 2001 Jun;7(3): 246-57. Available from: http://www.ncbi.nlm.nih.gov/pu bmed/11499403

12. Moriarty A. Pediatric epidural analgesia (PEA). Paediatr Anaesth. 2012 Jan;22(1):51-5.

13. Nelson KL, Yaster M, Kost-Byerly S, Monitto CL. A national survey of American Pediatric Anesthesiologists: patient-controlled analgesia and other intravenous opioid therapies in pediatric acute pain management. Anesth Analg. 2010 Mar 1;110(3):754-60.

14. Organizations TJCoAoH. Patient controlled analgesia by proxy. Sentinel Event Alert. 2004 Dec;20(33):1-2.

15. Dryden CM, McMenemin I, Duthie DJ. Efficacy of continuous intercostal bupivacaine for pain relief after thoracotomy. Br J Anaesth. 1993 May;70(5):508-10.

16. Hsieh MJ, Wang KC, Liu HP, et al. Management of acute postoperative pain with continuous intercostal nerve block after single port video-assisted thoracoscopic anatomic resection. J Thorac Dis. 2016;8(12):3563-71.

17. Joshi GP, Bonnet F, Shah R, et al. A systematic review of randomized trials evaluating regional techniques for postthoracotomy analgesia. Anesth Analg. 2008 Sep;107(3): 1026-40. 
18. Walker BJ, Long JB, De Oliveira GS, et al. Peripheral nerve catheters in children: an analysis of safety and practice patterns from the pediatric regional anesthesia network (PRAN). Br J Anaesth [Internet]. 2015 Sep;115(3): 457-62. Available from: http://www.ncbi.nlm.nih.gov/pu bmed/26205902

19. Simic D, Stevic M, Stankovic Z, et al. The Safety and efficacy of the continuous peripheral nerve block in postoperative analgesia of pediatric patients. Front Med (Lausanne) [Internet]. 2018;5:57. Available from: http://w ww.ncbi.nlm.nih.gov/pubmed/29594120

20. Liu SS, Wu CL. Effect of postoperative analgesia on major postoperative complications: a systematic update of the evidence. Anesth Analg [Internet]. 2007 Mar;104(3):689702. Available from: http://www.ncbi.nlm.nih.gov/pubm ed/17312231

21. Mowbray A, Wong KK, Murray JM. Intercostal catheterisation. An alternative approach to the paravertebral space. Anaesthesia. 1987 Sep;42(9):958-61.
22. Middaugh RE, Menk EJ, Reynolds WJ, Bauman JM, Cawthon MA, Hartshorne MF. Epidural block using large volumes of local anesthetic solution for intercostal nerve block. Anesthesiology. 1985 Aug;63(2):214-6.

(Received,

May 17, 2020)

(Accepted, October 28, 2020)

(J-STAGE Advance Publication, November 30, 2020)

Journal of Nippon Medical School has adopted the Creative Commons Attribution-NonCommercial-NoDerivatives 4.0 International License (https://creativecommons.org/licenses/by-nc-nd/4.0/) for this article. The Medical Association of Nippon Medical School remains the copyright holder of all articles. Anyone may download, reuse, copy, reprint, or distribute articles for non-profit purposes under this license, on condition that the authors of the articles are properly credited. 